\title{
ETNOZOOLOGIA E EDUCAÇÃO AMBIENTAL PARA ESCOLAS DA AMAZÔNIA: EXPERIMENTAÇÃO DE INDICADORES QUANTITATIVOS
}

\author{
ETHNOZOOLOGY AND ENVIRONMENTAL EDUCATION FOR SCHOOLS IN THE AMAZON: \\ EXPERIMENTATION OF QUANTITATIVE INDICATORS
}

\author{
ETNOZOOLOGÍA Y EDUCACIÓN AMBIENTAL PARA ESCUELAS DE LA AMAZONIA: \\ EXPERIMENTACIÓN DE INDICADORES CUANTITATIVOS
}

\author{
Paula Cristina Reale Rosa Bastos ${ }^{1}$ \\ Maria das Dores Correia Palha ${ }^{2}$ \\ Maria de Jesus da Conceição Ferreira Fonseca ${ }^{3}$ (in memoriam) \\ Alanna do Socorro Lima Silva ${ }^{4}$
}

Resumo Desenvolvido em escolas públicas de diferentes contextos ambientais e educacionais de Belém, no Pará, o estudo apresentado objetivou criar uma abordagem metodológica possível de ser reproduzida por qualquer escola de ensino fundamental ou médio na Amazônia, gerando informações sobre as interações homem-animal-ambiente e a evolução da consciência ecológica do alunado. Testaram-se cinco indicadores quantitativos: 'Diferenciação de animais silvestres e domésticos', 'Animais no prato', 'Proximidade aluno-animal', 'Sentimentos em relação à fauna' e 'Justificativas de falta dos alunos'. Obtiveram-se resultados significativos: na identificação do conhecimento prévio dos alunos sobre o conceito de animais silvestres-domésticos, verificou-se que em uma das escolas o avançar das séries não determinava maior capacidade de diferenciação dos animais; jacaré, tatu e tartaruga foram as espécies mais citadas pelos alunos nas duas escolas e constituíam o cardápio alimentar das famílias; foi comum a presença de animais domésticos e silvestres criados nos cômodos internos das casas, registrando-se altos percentuais de criações múltiplas de animais; sentimentos de 'querer matar' e 'medo/nojo' ainda foram bastante frequentes, principalmente para répteis, traduzindo a necessidade de maiores investimentos em educação ambiental; faltas por motivo de doença foram recorrentes e tinham estreita relação com animais. A metodologia é válida para etnozoologia e educação ambiental, adequando-se à realidade socioeconômica e ambiental das escolas.

Palavras-chave etnozoologia; educação ambiental; indicadores quantitativos.
Abstract Carried out in public schools in different environmental and educational contexts of Belém, state of Pará, Brazil, the study presented was designed to create a possible methodological approach to be reproduced by any primary or secondary school in the Amazon, generating information about the human-animal-environment interactions and the progress made in ecological awareness among the students. Five quantitative indicators were tested: 'Distinction between wild and domestic animals,' 'Animals on the plate,' 'Student-animal proximity,' 'Feelings regarding the fauna,' and 'Student absence justifications.' Significant results were obtained: In the identification of the students' prior knowledge about the concept of wild-domestic animals, it was found that at one of the schools, although students passed from one grade to the next, they were not necessarily more able to distinguish among the animals; alligators, armadillos, and turtles were the species students mentioned most frequently in the two schools, and they were on their families' food menus; keeping domestic and wild animals in the homes was common, and keeping multiple animals was frequently recorded; feelings of 'want to kill' and 'fear/disgust' were still quite common, especially with regard to reptiles, reflecting the need for greater investments in environmental education; absences due to illness were recurrent and were closely related with animals. The methodology is valid for ethnozoology and environmental education, and is appropriate for the socioeconomic and environmental realities of the schools.

Keywords Ethnozoology; environmental education; quantitative indicators. 


\section{Introdução}

As últimas duas décadas de nosso século vêm registrando um estado de profunda crise mundial. É uma crise complexa, multidimensional, cujas facetas afetam todos os aspectos de nossa vida - a saúde, o modo de vida, a qualidade do meio ambiente e das relações sociais, da economia, da tecnologia e da política (Capra, 2006).

A questão ambiental, mesmo com toda a sua complexidade, precisa ser estudada, posta em discussão, para que possíveis instrumentos de solução sejam criados. De empreendimentos tecnológicos a métodos de educação em sala de aula, qualquer iniciativa que some esforços na tentativa de minimizar ou impedir impactos ambientais é válida e urgente. Segundo Branco (1999), as questões ambientais são relativizadas por conta do comportamento ético que a humanidade adquiriu ao longo dos séculos. Uma grande dificuldade no que se refere à atitude ética no ser humano reside no fato muito peculiar e fundamental de que este, ao contrário de todos os demais seres, não se comporta como espécie, mas sim como indivíduo. A consciência e a vontade não são da comunidade, mas sim de cada indivíduo em particular, regidas de acordo com as necessidades encontradas.

No entanto, existe um sistema ao qual todo indivíduo é pertencente, o sistema cultural. A ética e a consciência ecológica somente se estabelecerão quando aliarmos ao nosso conhecimento racional uma intuição da natureza não linear do meio ambiente. Tal sabedoria intuitiva é característica das populações tradicionais, não letradas, especialmente as culturas dos índios, em que a vida foi organizada em torno de uma consciência altamente refinada do meio ambiente. Na corrente principal de nossa cultura, entretanto, foi negligenciado o cultivo da sabedoria intuitiva - o que pode estar relacionado com o fato de que, em nossa evolução, ocorreu uma crescente separação entre os aspectos biológicos e culturais da natureza humana (Capra, 2006).

Nas últimas décadas, desenvolveram-se bem mais as pesquisas sobre os chamados 'povos tradicionais', numa perspectiva interdisciplinar, construindo assim interfaces entre as ciências sociais e as da natureza. Mais recentemente, a partir dos anos 1980, têm sido valorizados os saberes de grupos indígenas e de comunidades tradicionais sobre a natureza, mas com uma orientação bem nítida, proveniente do debate sobre preservação de ecossistemas e biodiversidade. Reconhecem-se esses saberes e as formas de manejo a eles pertinentes como fundamentais na preservação da biodiversidade. Tornou-se extremamente importante, para intervir na crise ecológica, conhecer práticas e representações desses diferentes grupos, pois eles conseguiram, ao longo do tempo, elaborar um profundo conhecimento sobre os ecossistemas. Esse conhecimento lhes garantiu até hoje a reprodução de seu sistema social e cultural (Castro, 1998), provando que o velho modelo cien- 
tífico, cartesiano e mecanicista, perde cada vez mais espaço para a pesquisa sistêmica, baseada na visão ampliada e integrada aos modelos socioeconômicos e culturais (Parsons, 1951; Bertalanffy, 1973; Prigogine, 1996; Carvalho, 2005).

Socraticamente, Freire (2003) afirma que não há como admitirmos a existência de um homem totalmente descomprometido diante de sua circunstância. É condição de sua própria existência o seu compromisso com essa circunstância em que inegavelmente aprofunda suas raízes, podendo-se afirmar que o homem não pode viver autenticamente enquanto não se acha integrado com a sua realidade, criticamente integrado a ela e não alienado de sua cultura.

Na sequência de seu pensamento, Freire (2003) explica a cada vez maior inoperosidade dos processos educativos, sempre tão distantes das realidades locais. E completa afirmando que uma reforma na educação só será realmente observada quando o planejamento educacional for aliado às condições locais e regionais, feito sob medida para a cultura da região, diversificada, com investimento em novas metodologias, e quando se deixar definitivamente para trás o oferecimento de uma educação intensamente verbal e palavrosa.

Na busca por possíveis instrumentos de solução para os agravos ambientais especialmente na Região Amazônica, mediante uma abordagem metodológica sistêmica direcionada a escolas, é que se desenvolveram os três eixos centrais desta pesquisa: os estudos etnozoológicos, a educação ambiental (EA) e as interações complexas em saúde.

As atividades etnozoológicas planejadas para este trabalho propuseram-se captar do íntimo dos alunos as cargas de valores, percepções e sentimentos deles para com os animais. Trata-se de um desafio para os estudos etnozoológicos, uma vez que esta pesquisa foi realizada em duas áreas periféricas com distintos contextos de urbanização, distantes e bem diferentes das sociedades chamadas tradicionais, onde o contato com os animais é bem maior e as questões religiosas e hierárquicas ainda regem essas relações. Entretanto, mesmo na cidade ou nas chamadas áreas metropolitanas, as relações homem-animal-ambiente continuam existindo e merecem estudo aprofundado.

Segundo Reigota (2002), a escola tem sido historicamente o espaço indicado para discussão e aprendizado de vários temas urgentes e da atualidade, como resultado da sua importância na formação de cidadãos. É evidente que a escola deve estar sempre aberta ao conhecimento, inquietações e propostas de sua época, procurando consolidar inovações pedagógicas que contribuam para continuar cumprindo seu papel social. Dessa forma, a EA - com sua urgente e necessária contribuição para a formação de cidadãos mais comprometidos com as questões ambientais - surge como instrumento de sensibilização e, aliada aos estudos etnozoológicos e socioeconômicos, é tratada nesta pesquisa-ação como instrumento de mensuração da evolução alcançada em processos de conscientização, tendo como territórios escolas na Amazônia. Ao contrário dos trabalhos que fazem uma avaliação puramente 
qualitativa dos esforços em EA, este estudo demonstrou uma nova abordagem metodológica, baseada nas interações complexas EA-etnozoologia-saúde e em indicadores qualiquantitativos que demonstrem o quanto de mudanças positivas em relação à preservação de recursos naturais as novas gerações conseguem transparecer.

Inicialmente direcionado para o ciclo fundamental de ensino, este estudo não se apresenta como um modelo fechado, podendo ser adequado para outros ciclos e uso em escalas variadas, no âmbito do professor, individualmente ou em grupo, da escola ou de sistemas escolares mais complexos, abrangendo polos ou secretarias.

Dessa forma, pode-se afirmar que o objetivo geral do trabalho foi propor e validar inovações metodológicas baseadas nas interações homem-animal-ambiente que contribuam para a etnozoologia, as práticas da educação ambiental, a investigação em saúde e a prevenção de doenças em escolas da Amazônia. Teve como objetivos específicos: desenvolver estudos socioeconômicos e etnozoológicos em escolas de diferentes contextos ambientais e educacionais da Amazônia, que permitissem obter dados sobre o uso e o significado da fauna silvestre e seus produtos e das demais interações homem-animal-ambiente; propor inovações metodológicas para melhoria das atuais formas de levantamento de dados etnozoológicos e da interação homem-animal-ambiente, visando subsidiar ações mais eficientes para a educação ambiental e a prevenção de doenças em escolas da Amazônia; e comparar os resultados obtidos nas escolas pesquisadas para mostrar o nível de eficiência educacional que cada uma desempenha na formação de sujeitos ecológicos, bem como validar dinâmicas e indicadores.

É válido registrar que este estudo é também uma proposta para maior interação entre universidade e escola nas temáticas de estudos das relações de etnoconhecimento sobre a fauna silvestre e a educação ambiental, assim como de ampliação do espectro da pesquisa dos amplos contextos de saúde, por meio da relação da medicina veterinária com a saúde na escola e na família.

\section{Proposições comparativas: observações dos entornos e das realidades educativas}

As possibilidades ou proposições aqui descritas ilustram o valor da metodologia proposta, com base nos resultados de dinâmicas e indicadores testados e validados no âmbito de uma mesma escola ou em distintas realidades exemplificadas pelo contraste entre duas escolas. Considere-se ainda que o espectro de dinâmicas e indicadores passíveis de serem criados e validados, tendo por base essa proposta metodológica é amplo e dinâmico, a depender dos objetivos, da espacialidade e da temporalidade de sua adoção. 
Portanto, as análises estatísticas foram feitas mais no sentido de exercícios analíticos, utilizando-se o Programa SPSS Statistics 17 Multilanguage para promover o cruzamento das informações socioeconômicas ambientais com as obtidas como resultado da aplicação das dinâmicas desenvolvidas, de modo a ressaltar assim a validade do método, em especial dos indicadores qualiquantitativos formulados.

Este artigo é resultado de dissertação de mestrado (Bastos, 2013) do Programa de Pós-Graduação em Saúde e Produção Animal na Amazônia, da Universidade Federal Rural da Amazônia (PPGSPAA/Ufra) e teve o apoio do edital Procad-NF Ufra/Universidade Federal de Pernambuco (UFRPE)/Universidade Estadual de São Paulo (Unesp), Botucatu, com financiamento da Coordenação de Aperfeiçoamento de Pessoal de Nível Superior (Capes) do Ministério da Educação.

\section{Comparação entre as escolas}

Na escola A, por ela ter desde o ensino infantil a educação ambiental como eixo norteador, as respostas às atividades tenderam a ser mais positivas no sentido de conhecimento e preservação dos recursos faunísticos do que na escola B.

Pelo fato de a escola A estar inserida em uma ilha com presença de matas nativas e regeneradas, presumiu-se maior quantidade e diversidade de animais silvestres; portanto, o contato dos alunos com eles era mais intenso, com maior frequência de relações etnozoológicas, tais como o consumo alimentar de carne de caça e a prática do 'xerimbabismo', 5 em comparação com a escola B.

Por terem maior contato com animais silvestres, acreditava-se que os alunos da escola A teriam maior facilidade em diferenciá-los dos domésticos. As respostas das atividades tenderam a ser mais positivas com o avançar das séries, principalmente na escola A. Os efeitos das variáveis socioeconômicas das famílias dos alunos sobre os resultados das dinâmicas visando à EA e à etnozoologia foram diferentes entre as escolas.

\section{Análise das escolas individualmente}

As respostas às atividades não foram influenciadas pelo sexo, com exceção da atividade dos sentimentos, uma vez que é mais comum que meninos manifestem sentimentos/atitudes agressivas, expressos na dinâmica como 'querer matar' (por exemplo: atirar em passarinho, apedrejar lagartos, 'malinar' animais etc.). 
Turmas de mesma série, mas distintas quanto ao desempenho escolar, mostraram diferentes respostas às dinâmicas realizadas. Quanto maior a interação entre alunos e animais, maior o risco de doenças resultantes, conforme proximidade/contato.

Por terem maior discernimento das implicações legais que envolvem o consumo de animais silvestres, os adultos (pais ou responsáveis) mascararam a verdade quando indagados (por meio de questionários) sobre o consumo de carne de caça em comparação com as crianças (atividade 'animais no prato', em sala de aula).

\section{As escolas e seus contextos}

Escola A: representante de escola em zona periférica menos densa e com áreas insulares da região metropolitana do município de Belém. É uma escola do Sistema de Ensino do Município de Belém, localizada na ilha de Caratateua, distrito de Outeiro, distante $35 \mathrm{~km}$ da capital paraense. Possui aproximadamente 2.500 alunos, distribuídos, além da sede, em mais seis unidades pedagógicas situadas em três ilhas dos arredores de Belém (Cotijuba, Jutuba e Paquetá). É considerada no meio acadêmico e entre a população em geral como uma referência no ensino em EA, com um currículo em que o tema é abordado do ensino infantil ao curso técnico em meio ambiente (Figura 1).

Figura 1

Imagem via satélite da localização da escola A (1¹6'29.82"S 48²8'19.95"O)

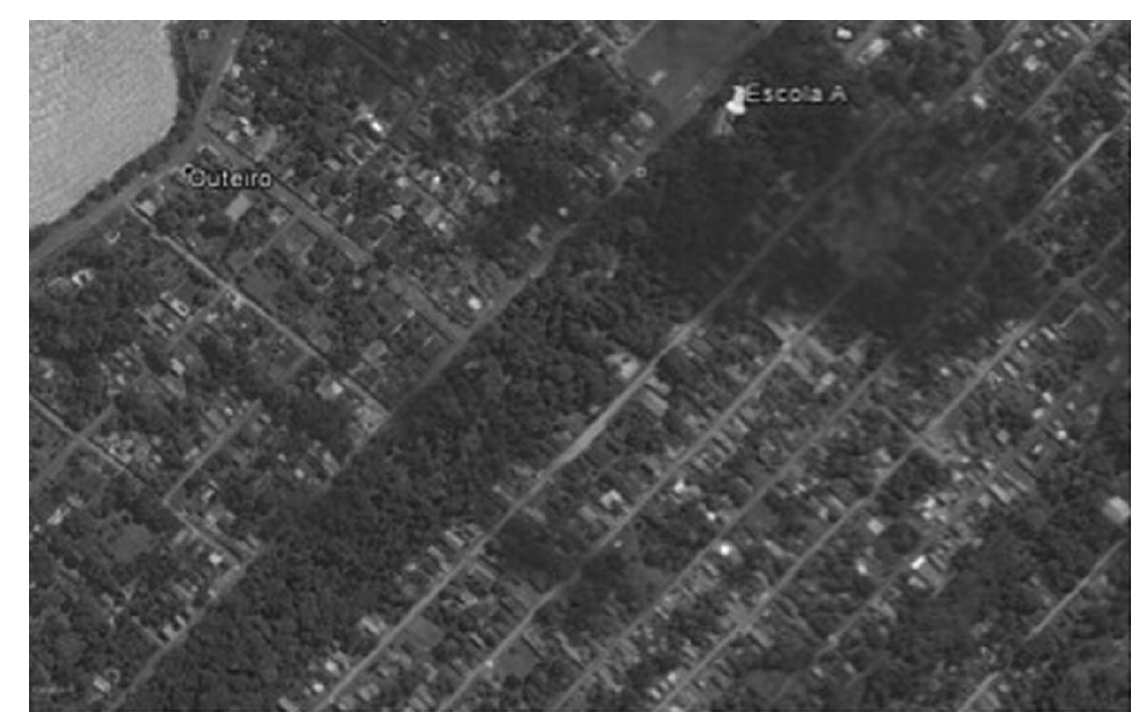

Fonte: Google Earth PRO. Data da imagem: 17 jun. 2015. Acesso em: 10 jun. 2016. 
Escola B: representante do contexto periférico urbano do município de Belém. Localiza-se no interior do campus da Ufra, no bairro da Terra Firme, distante aproximadamente sete quilômetros do centro da cidade. Funciona em dois turnos (manhã e tarde), com o ensino fundamental e médio. A escola atende, em média, 610 alunos por ano letivo, basicamente crianças e adolescentes do próprio bairro, e pertence ao Polo ou Unidade Regional de Educação (URE-6), que compreende as escolas estaduais dos bairros da Terra Firme e do Guamá.

Segundo a sua diretora no período da pesquisa, a escola seguia a proposta pedagógica da Lei de Diretrizes e Bases da Educação do Ministério da Educação, adotando o sistema de currículos mínimos (Figura 2).

Figura 2

Imagem via satélite da localização da escola B (1॰27'4.84"S 48²8'8.81"O)

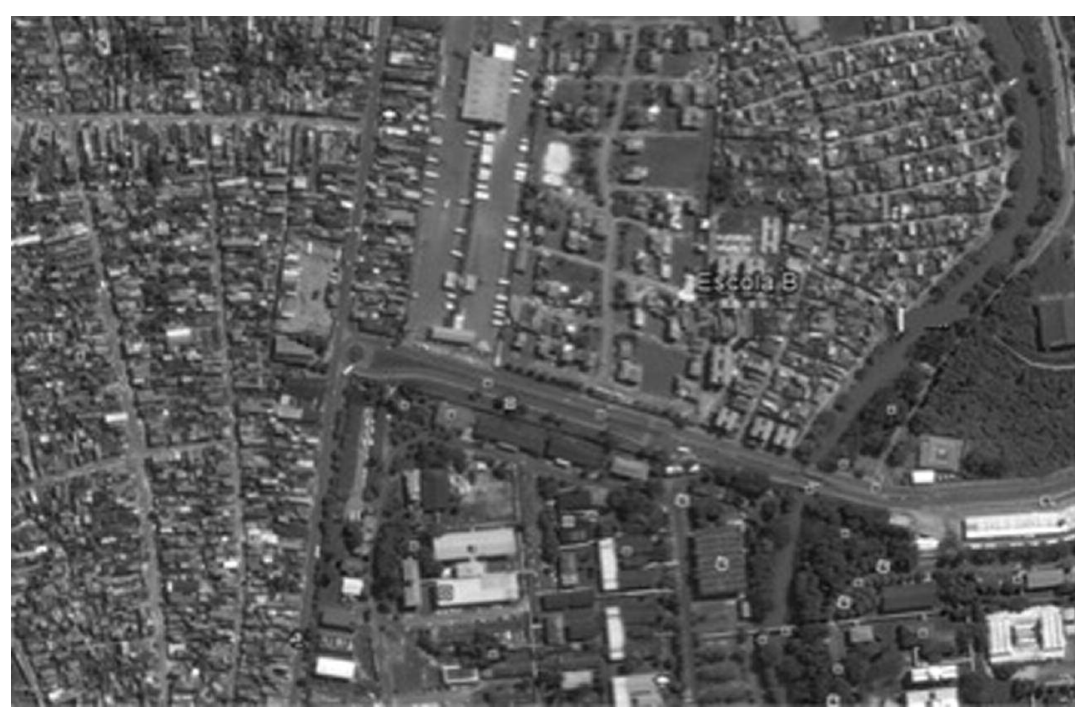

Fonte: Google Earth PRO. Data da imagem: 16 jul. 2015. Acesso em: 10 jun. 2016.

No início e no desenrolar do trabalho foram feitas reuniões com diretores, professores e colaboradores das escolas, para reconhecimento e integração dos atores envolvidos, apresentação da proposta, discussão da metodologia de trabalho com os alunos e pais/responsáveis, abordagem da importância das atividades de EA nas práticas da escola e da expansão destas à comunidade, além de discussão sobre a conservação do meio ambiente para a sociedade.

Essas reuniões foram de extrema valia, pois selaram o apoio entre as partes, retomando a parceria já existente entre a Ufra e as escolas envolvidas. As atividades programadas nas escolas contaram com o apoio dos professores, 
que ficavam livres para auxiliar na dinâmica e fazer adaptações, conforme o perfil de suas turmas - indicando, por exemplo, a melhor forma de aplicação, o melhor local (na sala de aula ou em outro espaço da escola), individualmente ou em grupo, de forma que a atividade pudesse fluir sem maiores complicações.

Além disso, o trabalho promoveu a aproximação dos pais/responsáveis, pois estes contribuíram com informações valiosas, por meio do preenchimento do questionário sociocultural e econômico, fonte de muitas correlações feitas neste trabalho.

\section{Elaboração do perfil socioeconômico, cultural e ambiental, e o contexto familiar dos alunos}

O ponto de partida para se conhecer o contexto familiar dos alunos e subsidiar ações subsequentes deste estudo se constituiu no levantamento do perfil socioeconômico, cultural e ambiental das famílias que integram as comunidades das duas escolas-alvo.

Um questionário simples, especialmente formulado, foi aplicado aos pais/responsáveis, com perguntas sobre bairro, número de pessoas na residência, pertences e estrutura da casa, trabalhadores por moradia, formas de atendimento médico utilizadas, tipo de medicação adotada pela família, grau de instrução escolar, situação trabalhista, renda média familiar, lugar de origem, opção religiosa, costumes alimentares, dentre outras.

Em 2011, os questionários socioculturais e econômicos foram aplicados para os pais ou responsáveis dos alunos do ensino infantil (alfabetização), $1^{a}, 3^{a}, 4^{a}$ e $5^{a}$ séries da escola A e para os pais ou responsáveis de alunos de $1^{\text {a }}$ a $4^{\text {a }}$ séries da escola $B$.

\section{Indicadores quantitativos em educação ambiental e etnozoologia para escolas da Amazônia}

Indicadores quantitativos relacionados à educação ambiental e à etnozoologia foram concebidos com base em dinâmicas realizadas nas escolas, indicadas a seguir.

\section{Dinâmica 1: diferenciação de animais silvestres e domésticos}

Nessa atividade, cada aluno recebia dois papéis A4 de cores diferentes (amarela e azul) e uma folha com a imagem em preto e branco de seis animais, dos quais três eram domésticos e três eram silvestres. Os alunos tinham que 
recortar os animais e colar aqueles que julgavam ser domésticos na folha azul e aqueles que achavam ser silvestres na folha amarela. Depois de devidamente colados, podiam colorir conforme sua imaginação ou seu conhecimento sobre a(s) cor(es) real(is) do(s) animal(is) como se apresenta(m) na natureza, uma vez que a pintura não foi avaliada.

\section{Dinâmica 2: animais no prato}

Para essa atividade foi criada uma figura de um prato em uma folha de papel A4, com espaço para que o aluno colocasse seu nome e série. Foi pedido que os alunos desenhassem ou escrevessem o nome dos animais que eles costumam comer ou que são consumidos em sua casa, dando destaque para os 'animais da mata' ou 'animais da floresta', termos utilizados para designar os animais silvestres. Todas as vezes em que os animais foram desenhados, procedeu-se à anotação dos nomes deles para evitar posteriores erros na interpretação dos desenhos. Os dados resultantes dessa atividade foram planilhados; os animais informados foram enumerados e separados entre domésticos e silvestres.

\section{Dinâmica 3: proximidade aluno-animal}

Nessa atividade, os alunos desenhavam em uma folha de papel A4 sua casa, com os devidos compartimentos internos e externos, o quintal e a rua, indicando se havia algum animal, quantos eram, a sua espécie e em qual espaço da casa esses animais costumavam permanecer. Os dados dessa atividade foram planilhados, separando-se animais domésticos de silvestres e seus locais no ambiente habitacional (quarto, sala, banheiro, cozinha, quintal, pátio e rua).

\section{Dinâmica 4: sentimentos em relação à fauna silvestre}

Para essa atividade foram criados seis painéis, que indicavam os seguintes sentimentos em relação aos animais silvestres: 'Quero ter ou cuidar', 'Não me interessa', 'Tenho medo ou nojo', 'Quero ver na mata', 'Quero matar' e 'Acho gostoso'. Cada criança recebeu um conjunto de figuras de animais de distintas classes (mamíferos, aves e répteis), em forma de cartões autocolantes, que facilmente poderiam ser afixados nos painéis. Embora as espécies variassem, cada conjunto mantinha o mesmo número total (cinco cartões) e a mesma proporção de espécimes por classe (dois mamíferos, dois répteis e uma ave). Foi solicitado que a criança olhasse para cada cartão e que, individualmente, o afixasse no painel que melhor expressasse o sentimento dela por aquele animal. 
Previamente, os cartões pertencentes a um mesmo conjunto de figuras foram marcados com um número comum, possibilitando identificar a criança sem que esta percebesse, estratégia utilizada como forma de se avaliar a individualidade dos sentimentos.

\section{Aspectos da saúde: justificativas de falta que se relacionam à tríade homem-animal-ambiente}

Com a dinâmica da proximidade aluno-animal previamente apresentada, analisada e discutida, realizou-se uma avaliação na secretaria da escola A sobre as faltas dos alunos, no sentido de se buscarem associações entre as espécies animais e o grau de proximidade com os alunos, além de eventuais agravos na sua saúde, mediante avaliação das fichas de justificativas de falta que eram mantidas e alimentadas em um programa de computador da escola.

De posse da informação sobre qual turma demonstrou maior proximidade com animais, retirada da dinâmica 3, investigou-se se os alunos dessa turma apresentaram alguma justificativa de falta no ano de 2011 que se pudesse inferir relacionada ao estreito contato com animais silvestres ou com animais domésticos.

\section{Análise dos dados das proposições: contrastes e corroborações}

Uma das grandes surpresas desta pesquisa foi a inexistência de uma ficha escolar detalhada dos alunos da rede pública de ensino. As secretarias de educação mantêm uma limitada ficha de informações a respeito da realidade socioeconômica, cultural e ambiental de seus alunos.

Autores como Penteado (2007) defendem a ideia de que a escola não é a única responsável pela educação do aluno, atribuindo à participação ativa dos pais ou responsáveis na vida escolar e dentro do seio familiar um fator preponderante para o desenvolvimento cognitivo e para a formação de um cidadão mais responsável.

A pesquisa comprovou que a não manutenção de fichas escolares que disponibilizem informações sobre o contexto do ambiente e modo de vida dos alunos limita as possibilidades de análises mais elaboradas sobre o desempenho do processo ensino-aprendizagem, deixando uma lacuna para que as instituições gestoras de ensino tenham maior compreensão dos pontos críticos desse processo e condições mais favoráveis ao norteamento de alternativas para a melhoria da educação como um todo.

Considerando-se apenas o ano de 2011, aplicou-se o questionário sociocultural e econômico aos pais ou responsáveis, totalizando seis turmas 
(jardim I, 1 ${ }^{\mathrm{a}}, 3^{\mathrm{a}}, 4^{\mathrm{a}}$ e duas turmas de $5^{\mathrm{a}}$ série) da escola A, com um total de 96 questionários. Já na escola $\mathrm{B}$, tais questionários compreenderam seis turmas $\left(1^{\mathrm{a}}, 2^{\mathrm{a}}\right.$, duas turmas de $3^{\mathrm{a}}$ e duas de $4^{\mathrm{a}}$ série), perfazendo 194 questionários.

Os resultados demonstraram que a condição econômica dos alunos era precária, revelando um perfil de renda uniforme para as duas escolas. Essa condição implicava diretamente o desempenho escolar do aluno, que muitas vezes se mantinha na escola apenas em busca da merenda escolar que lhe era oferecida. Segundo Custódio (2008), a força da nutrição é um dos fatores que podem influenciar no desenvolvimento intelectual do indivíduo, desenvolvendo o cérebro, melhorando a inteligência e combatendo desgastes causados no dia a dia. O bem-estar advindo de uma boa alimentação é fator importante para que o aluno se mantenha concentrado e disposto a realizar as atividades de sala e extraclasse.

$\mathrm{Na}$ escola A, mais de $40 \%$ dos responsáveis tinham apenas o ensino fundamental incompleto, ao passo que na escola B esse grau se elevava até o ensino médio completo. No entanto, em EA, acredita-se que o nível de escolaridade dos pais não influencia na transmissão de conceitos básicos sobre consciência ecológica.

Na escola B, o percentual de responsáveis desempregados representava mais da metade da amostra $(55,38 \%)$, condição essa que nitidamente se destacava em relação às outras situações empregatícias. Já na escola A, apesar de a porcentagem de desempregados também ser elevada $(32,61 \%)$, esse status acabou não tendo destaque, uma vez que se percebeu um equilíbrio entre as outras situações empregatícias - o que pode estar associado ao fato de que na comunidade em que a escola A está inserida há maior tendência ao trabalho informal, que compreende os percentuais de autônomos e de empregados sem carteira assinada.

Tanto na escola A quanto na escola B, a maioria dos alunos (51,85\% e $57,95 \%$, respectivamente) era de famílias católicas, embora a diferença não fosse significativa. Seguia-se a religião evangélica $(41,98 \%$ e 37,95\%, respectivamente). A religiosidade tinha relação com diversos padrões de comportamento de seus adeptos. Essa questão pode estar associada a padrões comportamentais considerados positivos para o processo de ensino-aprendizagem e de formação do cidadão, incluindo sua consciência ambiental, por exemplo. Em artigo sobre religiosidade e meio ambiente, Palha e Tourinho (2009) afirmam que a religião como lógica indutora do racionalismo ambiental deriva da função que ela exerce (ou pode exercer) como fator de integração social. Por isso, as crenças, os dogmas e as atitudes relacionadas a uma religião podem configurar relações positivas ou negativas entre o homem e os recursos naturais.

Nas duas escolas, a maior parte das famílias fazia uso de medicamentos oriundos de farmácia ( $84,04 \%$ na escola A e $87,7 \%$ na escola B). Vale 
ressaltar que nesse item do questionário os responsáveis podiam marcar mais de uma alternativa, permitindo que as informações numéricas fossem agrupadas nas categorias de análise: farmácia, feira e caseiro.

A verificação de que o consumo de medicamentos de origem caseira por parte das famílias da escola A era significantemente superior ao registrado na escola B $(35,79 \%$ e $11,73 \%$, respectivamente) não é uma surpresa; pode-se explicar pelo fato de que a comunidade da escola A ainda mantinha maior proximidade com recursos naturais, tanto florísticos quanto faunísticos, em razão da presença de áreas de matas, reservas e do estreito contato com o rio Maguari. Esses espaços naturais guardam essências, raízes, animais, cascas e outros produtos usados há gerações como medicamentos e que são extraídos gratuitamente, saindo muito menos custosos do que os remédios vendidos nas farmácias.

O emprego etnomédico de espécies da fauna silvestre, segundo Silva (2008), tem sido frequente em comunidades urbanas e rurais do Brasil, mostrando-se significativo o número de espécies ameaçadas de extinção, mas que ainda assim são de grande importância no fornecimento de subprodutos para fins terapêuticos na cura de diversas doenças. Para os esforços da educação ambiental, esses elementos são importantes e precisam ser considerados, não para se trabalharem ideias castradoras quanto à extração de recursos, mas para a busca de tentativas de se fazer com que a comunidade reflita sobre seus padrões de uso, substituindo práticas insustentáveis por práticas mais limpas.

O local de procedência dos entrevistados foi pesquisado porque se atribui a ele o norteamento de hábitos culturais. Mais da metade das famílias das duas escolas era originária de Belém. Das demais famílias, advindas do interior do estado do Pará, diversas foram as localidades citadas. Considera-se que os alunos oriundos de outros estados, conforme sua localização, mantinham menor identidade com o meio regional que os locais.

Baía Júnior (2006) afirma que o comércio de animais silvestres está principalmente relacionado à questão cultural, havendo influência de ex-moradores dos interiores que se deslocam para os centros urbanos, mas não perdem a ligação com as tradições culturais e de forma frequente encomendam carne de caça para seus familiares que permaneceram no interior, ou mesmo tornam-se intermediários da caça sob encomenda.

A pesquisa sobre os hábitos alimentares de uma população pode sugerir interpretações interessantes, tanto sobre a cultura ou os costumes quanto sobre outros índices como renda, acessibilidade e preferências. Em relação ao consumo de carne de caça, que foi bastante inferior em detrimento do consumo de outros tipos de alimentos, o percentual registrado para a escola $\mathrm{B}$ foi um pouco superior ao da escola A $(36,73 \%$ e $34,21 \%$, respectivamente). Vê-se que, mesmo em menor proporção, o hábito do consumo alimentar de 
carne de caça ainda era uma realidade até mesmo para áreas extremamente urbanas da Amazônia, como é o caso da comunidade onde a escola B se encontra.

\section{Etnozoologia e educação ambiental para as escolas}

A dificuldade na obtenção de dados sobre a caça e as formas de uso da fauna no Brasil - e em particular na Amazônia - se dá em razão do receio das pessoas em prestarem informações e, a partir de então, tornarem-se passíveis de represálias ou penalidades por parte de órgãos ambientais. Essa realidade motivou a idealização e o desenvolvimento da pesquisa etnozoológica nas escolas, pela maior possibilidade de obtenção discreta e não invasiva de informações acerca da caça e do uso da fauna, mediante a mesclagem desses estudos às práticas de EA. Por essa razão, buscou-se nesse estudo o estabelecimento de parâmetros que pudessem ser usados como indicadores para a mensuração das relações existentes entre o homem e os animais.

Vale lembrar que a intenção das atividades propostas não foi esgotar os temas abordados, mas sim propor metodologias e sistemas de validação que contribuíssem para as aferições qualiquantitativas de mudanças de comportamento em relação às questões ambientais. Portanto, resultados mais efetivos do ponto de vista do rigor estatístico poderão surgir caso a metodologia aqui proposta venha a ser implantada no âmbito de turma(s), escola(s), polo(s) escolar(es) ou secretaria(s) de educação.

Na dinâmica 1, sobre diferenciação entre animais silvestres e domésticos, entendeu-se que havia necessidade de se avaliar o nível de conhecimento prévio dos alunos sobre conteúdos importantes para a temática ambiental animal. Saber diferenciar animais silvestres de animais domésticos permite que o aluno consiga conhecer melhor as espécies, fazendo associações com seu habitat, seus hábitos alimentares e outros aspectos importantes da ecologia dos animais, da conservação da(s) espécie(s) e do ambiente dos qual(is) este(s) necessita(m) para continuar existindo.

Acreditava-se que os alunos das séries mais avançadas registrariam média maior de acertos na atividade realizada. No entanto, ao nível de significância de 5\% (P - valor $=0,095)$ na escola $\mathrm{A}$, todas as turmas tiveram média de acertos iguais. Demonstrou-se quantitativamente que, nessa escola, o fato de pertencer a uma série mais avançada não influenciou no maior conhecimento sobre animais domésticos e silvestres.

Pode-se comentar ainda o desempenho da turma de $5^{\text {a }}$ série (Cobra-Grande) da escola A, que apresentou a menor das médias de acertos totais. Essa era uma turma formada em sua maioria por repetentes e alunos considerados menos comportados, estratégia que vinha sendo adotada pela coordenação pedagógica da escola com relação às turmas que se encaixavam nessa 
condição, com o argumento de nelas concentrar esforços na tentativa de aumentar o rendimento dos estudantes.

Outra observação pertinente é que os alunos da escola A conseguiram distinguir melhor os animais silvestres que os domésticos - o que podia estar relacionado ao fato de esses alunos terem, ainda, maior contato com alguns desses animais, reconhecendo-os em matas ainda existentes na própria escola ou próximo a suas casas.

Já na escola $\mathrm{B}$, ao nível de significância de 5\% (P - valor $=0,005)$, pelo menos uma turma apresentou média de acertos diferente. Percebeu-se que, nessa escola, quanto mais o aluno avança nas séries, maior a sua capacidade de diferenciação dos animais.

Traçando-se um comparativo entre as médias de acertos entre as duas escolas, concluiu-se que também ao nível de significância de $5 \%$, a escola A e a escola B apresentaram médias de acertos diferentes em relação a essa atividade.

Considera-se que o reconhecimento e a classificação dos animais são peças fundamentais para programas que envolvam a conscientização para a conservação de espécies. Afinal, como diz Redford (1997), uma floresta vazia é uma floresta condenada, e o maior conhecimento das espécies, juntamente com esforços para a conscientização sobre a importância ecológica e cultural delas, pode contribuir para limitar os crescentes déficits faunísticos.

Na dinâmica 2, sobre os animais no prato, confirmou-se o grande costume regional de se consumir carne de caça, que em muitas comunidades amazônicas chega a ser a principal fonte proteica das famílias. Tal atividade demonstrou o nível desse consumo, gerando um indicador quantitativo que pode ser avaliado no decorrer dos anos. Esses dados, além de analisados intra e interturmas de uma mesma escola, permitiram contrastar realidades entre as escolas trabalhadas.

Na Região Amazônica, o uso de animais da fauna para fins alimentares de subsistência sempre se constituiu em uma prática comum e corriqueira, conforme apontado por Palha, Sardinha e Hamoy (1999). Nessa atividade etnozoológica percebeu-se que, mesmo em menor escala, tal prática continua em pleno vigor, alimentando o hábito cultural de consumo desses animais.

De acordo com o verificado na comparação entre os desenhos das crianças das duas escolas, verificou-se maior registro de animais silvestres no prato dos alunos da escola A ( $\mathrm{N}$ total= 352); já na escola B esse $\mathrm{N}$ foi de 216 .

As dez espécies mais citadas em ordem de maior para menor consumo e que estavam no cardápio alimentar das famílias das duas escolas são apresentadas na Tabela 1. 
Tabela 1

\begin{tabular}{cc}
\hline Lista de animais silvestres que faziam parte do cardápio alimentar das famflias \\
\hline Animais citados & No de citações feitas pelos alunos das duas escolas \\
\hline Jacaré & 77 \\
Tatu & 64 \\
Tartaruga & 46 \\
Paca & 36 \\
Cobras & 28 \\
Preguiça & 26 \\
Mucura & 23 \\
Passeiriformes & 22 \\
Capivara & 18 \\
Iguana & 15 \\
\hline
\end{tabular}

Fonte: As autoras.

Percebe-se que ambas as escolas compartilhavam de um mesmo cardápio de animais silvestres. No entanto, na escola B houve a citação do consumo de carne de macaco (quatro citações), o que não foi evidenciado na escola A. Segundo as normas descritas no código sanitário para os animais terrestres da Organisation Mondiale de la Santé Animale (2008), o risco de se carrearem patógenos causadores de zoonoses está relacionado à posição taxonômica e à região de origem de primatas não humanos. O risco também de se carrearem agentes zoonóticos é maior em primatas capturados na natureza do que em animais criados em cativeiro. Vale lembrar que animais silvestres são considerados hospedeiros reservatórios de uma infinidade de agentes patogênicos.

Animais chamados de 'caça de primeira', como veado e paca, mesmo tendo sido citados, já não eram vistos nos arredores das escolas, especialmente da escola $\mathrm{B}$, o que alimenta a hipótese de que há um intenso tráfico desses animais oriundos de diversos municípios interioranos do estado do Pará, em direção à capital para alimentar tal hábito.

Essa metodologia permitiu inferir que mais esforços precisam ser realizados na tentativa de frear a caça predatória e fazer com que as comunidades adotem práticas de caça ou realizem manejo delas de forma mais sustentável.

Sabe-se que os humanos compartilham espaços geográficos, habitats e patógenos com grande variedade de animais domésticos e silvestres. Alterações ambientais de cunho antropogênico atuam nesse equilíbrio ecológico entre hospedeiro e parasito, levando à emergência de doenças (Daszak 
e Cunningham, 2002). Portanto, deve-se considerar com atenção as interações homem-animal-ambiente, principalmente aquelas em que há uma relação de proximidade muito estreita com homem-animal considerando-se aqueles de alto risco zoonótico, como é o caso dos primatas (macaco).

Na dinâmica 3, sobre a proximidade aluno-animal, caracterizou-se um indicador valioso para traçar correlações inerentes aos aspectos etnozoológicos e de saúde. O estreito contato com os animais pode permitir inferências quanto ao valor sentimental de cada espécime e/ou espécie, a um agravo de saúde, aos modos de criação e até mesmo a um impacto ambiental.

Notou-se que na escola B os percentuais eram mais elevados tanto para a criação de animais domésticos quanto para os animais silvestres em relação à escola A. Essa situação pode ser responsável por uma infinidade de doenças que afetavam a saúde dos alunos e seus familiares, tornando-se motivo para faltas constantes durante o ano letivo. De acordo com Dabanch (2003), o contato mais próximo entre homem e animal pode causar inconvenientes tais como o risco de mordeduras e alergias, em razão do contato e da propensão ao desenvolvimento de zoonoses importantes.

Também se notou que a criação de animais silvestres é maior na escola A. Somando-se a criação dentro e fora de casa, tem-se que 38,60\% dos alunos criavam alguma espécie de animal silvestre. Na escola B, esse percentual era de $20,74 \%$. A criação de animais silvestres constitui-se um fator cultural na Amazônia. Segundo Palha, Sardinha e Hamoy (1999), a prática do xerimbabismo ocupa o segundo lugar dentre os usos dos animais silvestres pelas comunidades ribeirinhas, perdendo apenas para o uso alimentar.

Outra forma de se demonstrar o alto grau de transferência ou trânsito de patógenos é por meio da quantidade de pessoas que criam várias espécies de animais silvestres e domésticos em um mesmo espaço. O contato muito próximo favorece a disseminação e as possíveis adaptações por parte dos microrganismos. A maior percentagem (30\%) de criação múltipla foi registrada na escola A e pode ser explicada pela maior presença de quintais nas casas dos alunos, onde os animais eram criados em um mesmo espaço, mas para fins diversos.

Se, de um lado, estão as doenças relacionadas ao estreito contato entre homem e animal, intensificado à medida que a população humana aumenta, de outro estão as problemáticas relações que envolvem a criação e o bem-estar dos animais, sejam estes de criação, sejam de estimação ou de vida livre. Sobre isso, Palha (2012) afirma que novas atitudes e definições são necessárias para melhor servir à saúde das populações e aos animais dos quais elas dependem.

Câmara e Tambellini (2003) já enfatizavam o uso da epidemiologia no desenvolvimento de ações de vigilância pela definição de indicadores de saúde para um sistema de informação, além do desenvolvimento de ativi- 
dades de monitoramento dos impactos das ações de mitigação e controle. Dessa forma, a escola é o espaço propício para se estudar e aplicar essas ações (Brasil, 2009), uma vez que tem o papel social da formação e consegue englobar grande parcela de uma comunidade (comunidade escolar).

Na dinâmica 4, sobre os sentimentos dos alunos em relação à fauna, preconizou-se que um maior nível de conscientização levaria os alunos a afixarem maior quantidade de figuras no painel que demonstrava o sentimento mais favorável de 'Querer ver na mata', em oposição aos sentimentos mais desfavoráveis de 'Querer ter ou cuidar' ou de 'Querer matar'. No Quadro 1, pode ser observado o perfil dos sentimentos demonstrados nos painéis em cada turma nas duas escolas. Tem-se a porcentagem total de figuras afixadas em cada painel e a porcentagem de alunos que afixaram pelo menos uma figura por sentimento e por classe animal.

Quadro 1

\begin{tabular}{|c|c|c|}
\hline \multirow{2}{*}{$\begin{array}{l}\text { Sentimento por tipo } \\
\text { de animal }\end{array}$} & \multicolumn{2}{|c|}{ Escola } \\
\hline & Escola A & Escola B \\
\hline Matar & $48,67 \%$ & $40,00 \%$ \\
\hline Mamífero & $18,58 \%$ & $5,00 \%$ \\
\hline Ave & $7,96 \%$ & $6,25 \%$ \\
\hline Réptil & $41,59 \%$ & $32,50 \%$ \\
\hline Medo ou nojo & $56,64 \%$ & $55,00 \%$ \\
\hline Mamífero & $18,58 \%$ & $22,50 \%$ \\
\hline Ave & $10,62 \%$ & $6,25 \%$ \\
\hline Réptil & $41,59 \%$ & $45,00 \%$ \\
\hline Ver na mata & $74,34 \%$ & $78,75 \%$ \\
\hline Mamífero & $56,64 \%$ & $66,25 \%$ \\
\hline Ave & $30,97 \%$ & $35,00 \%$ \\
\hline Réptil & $30,97 \%$ & $26,25 \%$ \\
\hline Acha gostoso & $32,74 \%$ & $28,75 \%$ \\
\hline Mamífero & $16,81 \%$ & $21,25 \%$ \\
\hline Ave & $6,19 \%$ & $1,25 \%$ \\
\hline Réptil & $16,81 \%$ & 0,125 \\
\hline Não se interessa & $30,97 \%$ & $36,25 \%$ \\
\hline Mamífero & $17,70 \%$ & $25,00 \%$ \\
\hline Ave & $7,08 \%$ & $7,50 \%$ \\
\hline Réptil & $10,62 \%$ & $10,00 \%$ \\
\hline Ter ou cuidar & $78,76 \%$ & $81,25 \%$ \\
\hline Mamífero & $40,71 \%$ & 0,2625 \\
\hline Ave & $61,95 \%$ & $43,75 \%$ \\
\hline Réptil & $34,51 \%$ & $45,00 \%$ \\
\hline
\end{tabular}

Fonte: As autoras. 
Pôde-se notar na resposta dos alunos das duas escolas a expressão histórica e cultural que rege as relações entre o homem e os animais. A manifestação de medo e nojo dos répteis, por exemplo, é herança da caracterização de animais maus, perigosos, venenosos, transmitida desde o início dos tempos. Para Whitfield e colaboradores (2000), o declínio global dos répteis é fruto dessas caracterizações históricas que deixam de apontar as contribuições positivas de tais animais para a conservação do equilíbrio da natureza dentre elas a de fortes indicadores de qualidade ambiental. Além disso, a degradação de habitats, a introdução de espécies invasoras, a intensa poluição, doenças, o uso insustentável e as alterações climáticas contribuem em grande escala para esse declínio.

Notou-se também que as porcentagens dos sentimentos de 'Querer ver na mata' (74,34\% da escola A e 78,75\% da escola B) e de 'Querer ter ou cuidar' $(78,76 \%$ da escola A e $81,25 \%$ da escola B) eram muito próximas quando se considerava a conscientização segundo a qual era mais importante ver o animal na natureza em vez de preso, engaiolado, mantido em casa, de forma que houvesse mudanças de atitude a médio ou longo prazos. A proposta era que as escolas criassem seus próprios programas ou atividades que colocassem os alunos em maior contato com a natureza, sem negligenciar a informação teórica que também poderia ser oferecida de forma lúdica.

Após a aplicação das atividades formais e não formais de educação ambiental e mediante as análises quali-quantitativas, podem ser feitas as correlações com as características socioeconômicas, culturais e ambientais dos alunos. A escola pode também promover encontros com os pais para demonstração dessa e das outras atividades promovidas com os alunos, a fim de que eles também percebam a importância da mudança de atitudes.

Descola (1998) afirma que, na prática, as manifestações de simpatia pelos animais são ordenadas em uma escala de valor, cujo ápice é ocupado pelas espécies percebidas como as mais próximas do homem em razão de seu comportamento, fisiologia, faculdades cognitivas ou da capacidade que lhes é atribuída de sentir emoções. Naturalmente, os mamíferos são os mais bem aquinhoados nessa hierarquia do interesse, independentemente do meio onde vivem.

Para Santos Fita e Costa Neto (2007), o conhecimento zoológico tradicional é sempre situacional e modificável. Ele pode variar qualitativa e quantitativamente, inclusive de acordo com gênero, faixa etária e nível de empatia com o animal. Estudos demonstram que o fator emocional é que direciona a percepção e a quantidade de informações sobre determinado objeto. Se um animal é culturalmente percebido como feio, nojento e potencialmente capaz de transmitir doenças, provavelmente muito pouco se saberá a seu respeito. Assim, essa atividade trouxe informações preciosas para demonstrar os sentimentos etnozoológicos nas duas comunidades escolares pesquisadas. Contribuiu ainda para a proposição de indicadores de sucesso em educação 
ambiental, cabíveis de serem adotados por qualquer escola, pois além de demandarem baixo custo para a sua aplicação, eles conseguem de forma satisfatória adaptar-se aos efeitos regionais.

\section{Aspectos da saúde: justificativas de falta que relacionam a tríade homem-animal-ambiente}

A pesquisa em etnozoologia e educação ambiental abre um leque de possibilidades para a investigação epidemiológica de uma variedade de enfermidades evidenciadas no alunado no decorrer do ano letivo. Durante 2011, na escola A, vários professores se depararam com a difícil tarefa de 'diagnosticar' enfermidades em seus alunos, uma vez que estes, mesmo doentes, muitas vezes frequentavam as aulas.

De acordo com os resultados da atividade 'Proximidade aluno-animal', verificou-se que as turmas de $5^{a}$ série da escola A (Cobra-Grande e Curupira) foram as turmas em que se registrou o maior número de alunos que possuíam animais criados em suas casas, domésticos e silvestres. Mediante a utilização das fichas de justificativas de falta dos alunos como indicador quantitativo de aspectos da sua saúde, apresentaram-se, por meio de proporções, as correlações observadas entre o resultado da dinâmica de proximidade - mais especificamente sobre a criação de animais domésticos e silvestres dentro de casa - e a ocorrência de doenças ou sintomas possivelmente relacionados a esse contato.

Dentre os alunos faltosos, 21,05\% relacionavam-se aos que criavam pelo menos um animal, doméstico ou silvestre, nos espaços internos da casa, e que faltaram à aula por motivo de doença em 2011. Dos animais domésticos criados, cachorros e gatos foram as espécies mais citadas; já entre os silvestres, destacaram-se as tartarugas e os macacos.

A criança de hoje deve crescer entendendo que o ambiente não é apenas o somatório das partes que o compõem, mas é também a inter-relação dessas partes com o todo, ou seja, é um conjunto complexo como uma unidade que contém a diversidade em suas relações antagônicas e complementares de forma muitas vezes simultânea (Guimarães, 2006). E como promover o ensino ou moldar esse cidadão ecologicamente correto? Moraes (2003) usa o termo 'abordagem relacional', com o qual fundamenta ações pedagógicas baseadas no estudo das relações para a criação de condições que contribuam para a construção de um conhecimento integrado do mundo, considerando-se a complexa rede de conexões existente entre seus componentes físico-químicos, biológicos, socioeconômicos e culturais. Tal abordagem habilita maior aproximação em relação à complexidade da realidade socioambiental global e às especificidades das realidades regionais. 


\section{Considerações finais}

Pode-se afirmar que o questionário socioeconômico e ambiental utilizado nesta pesquisa foi um instrumento válido para o diagnóstico, o entendimento e a busca de soluções para uma série de problemas gerados nos âmbitos escolar, familiar e da comunidade do alunado, devendo ser adequado à realidade do(s) interessado(s), sejam professores, sejam escolas ou unidades gestoras.

Esta pesquisa validou quatro indicadores de relações etnozoológicas e de EA ('Diferenciação de animais silvestres e domésticos', 'Animais no prato', 'Proximidade aluno-animal' e 'Sentimentos em relação à fauna'), baseados em análises qualiquantitativas construídas mediante a verificação estatística dos resultados das atividades com os alunos do ciclo fundamental de ensino de duas escolas de diferentes contextos socioculturais e ambientais da Amazônia.

$\mathrm{Na}$ forma de um ensaio experimental, a pesquisa também demonstrou como as justificativas de faltas dos alunos podem estar associadas aos indicadores de relações etnozoológicas, gerando informações sobre a saúde do estudante, inclusive de sua família - de modo a auxiliar na proposição de ações específicas de controle e prevenção das principais doenças que levam às faltas durante $o$ ano letivo.

Não se trata de uma proposta fechada, principalmente porque alcançou apenas o ciclo fundamental de ensino, mas pode funcionar como base para diagnoses mais eficientes dos processos educativos, para uma conscientização ecológica em programas desenvolvidos pelas próprias escolas ou por outras instituições governamentais e não governamentais. Passível de modificações segundo as especificidades da região onde as escolas se encontram, essa metodologia destacou-se por ser de baixo custo, de simples aplicação e por conseguir de forma ímpar preencher lacunas encontradas nas formas de verificação e reconhecimento dos contextos socioeconômico, cultural, sanitário e ambiental dos alunos.

Nesta pesquisa, as análises puderam demonstrar contrastes e igualdades entre duas escolas em termos de conscientização ecológica - e apontaram deficiências desse ramo do ensino até mesmo na escola que era considerada, no meio educacional, uma referência em EA. As informações captadas foram consideradas preciosas e essenciais, podendo ser transformadas no alicerce de ações estratégicas para melhorias nas áreas da educação, do ambiente e da saúde, oferecendo respostas mais eficientes e de maior credibilidade.

A pesquisa forneceu também embasamento para justificar a necessária introdução do médico-veterinário no Programa de Saúde na Escola, assim como na Estratégia Saúde da Família, para entre outras ações investigar o potencial epidemiológico que as relações etnozoológicas podem representar na emergência e reemergência ou surgimento de doenças. 
A aplicação dessas metodologias pode gerar resultados que ajudem a modificar as atitudes predatórias, de modo a estabelecer novas relações entre homem e natureza, marcadas pelo compromisso com o ambiente e com a preservação dos recursos para as próximas gerações.

\section{Colaboradores}

Paula Cristina Reale Rosa Bastos é responsável pela concepção, delineamento e redação do artigo. Maria das Dores Correia Palha e Maria de Jesus da Conceição Ferreira Fonseca (in memoriam) atuaram, respectivamente, como orientadora e co-orientadora da pesquisa, cooperaram na redação final e fizeram a revisão crítica do manuscrito. Alanna do Socorro Lima Silva participou mediante a aplicação das dinâmicas e na redação desta parte do artigo. Não houve financiamento e não há conflito de interesses.

Resumen Desarrollado en escuelas públicas de diferentes contextos ambientales y educativos de Belém, en el estado de Pará, Brasil, el estudio presentado buscó crear un enfoque metodológico que se pudiera reproducir en cualquier escuela de la enseñanza fundamental o media, en la Amazonia, generando información sobre las interacciones hombre-animal-ambiente y la evolución de la conciencia ecológica del alumnado. Se probaron cinco indicadores cuantitativos: 'Diferenciación de animales silvestres y domésticos', 'Animales en el plato', 'Proximidad alumno-animal', 'Sentimientos con relación a la fauna' y 'Justificativas de falta de los alumnos'. Se obtuvieron resultados significativos: en la identificación del conocimiento previo de los alumnos sobre el concepto de animales silvestres-domésticos, se observó que en una de las escuelas, el avanzar de grado no determinaba mayor capacidad de diferenciación de los animales; yacaré, tatú y tortuga eran las especies más citadas por los alumnos en las dos escuelas y constituían el menú familiar; era común la presencia de animales domésticos y silvestres criados en los cuartos de las casas, registrándose altos porcentajes de crías múltiples de animales; sentimientos de 'querer matar' y 'miedo/asco' todavía eran bastante frecuentes, principalmente para reptiles, lo que traduce la necesidad de mayores inversiones en educación ambiental; faltas por motivo de enfermedad eran recurrentes y guardaban estrecha relación con animales. La metodología es válida para la etnozoología y educación ambiental, adecuándose a la realidad socioeconómica y ambiental de las escuelas.

Palabras clave etnozoología; educación ambiental; indicadores cuantitativos. 


\section{Notas}

1 Fundação Prefeitura Municipal de Belém, Centro de Referência em Educação Ambiental Escola Bosque Professor Eidorfe Moreira, Belém, Pará, Brasil.

<pcrbastos@hotmail.com>

Correspondência: Fundação Centro de Referência em Educação Ambiental Escola Bosque Professor Eidorfe Moreira, Prefeitura de Belém, Avenida Nossa Senhora da Conceição, s/n, Outeiro, CEP 66815-000, Belém, Pará, Brasil.

2 Universidade Federal Rural da Amazônia, Instituto Socioambiental e de Recursos Hídricos, Belém, Pará, Brasil

$<$ faunaufra@gmail.com>

3 Universidade do Estado do Pará, Belém, Pará, Brasil.

4 Universidade Federal Rural da Amazônia, Belém, Pará, Brasil.

$<$ alannalima@gmail.com>

5 O termo 'xerimbabismo' é um neologismo que os autores adotaram, a partir do substantivo comum 'xerimbabo' (do tupi xeri'mawa, 'minha criação'). Significa, de acordo com Ferreira (1986, p. 1.797), "qualquer animal de criação ou estimação", usualmente empregado na Amazônia oriental em referência a um animal silvestre de estimação.

\section{Referências}

BAÍA JÚNIOR, Pedro C. Caracterização do uso comercial e de subsistência da fauna silvestre no municipio de Abaetetuba, Pará. 128 fls. Dissertação (Mestrado em Ciência Animal) Universidade Federal do Pará, Belém, 2006.

BASTOS, Paula. C. R. Etnozoologia e educação ambiental para escolas da Amazônia: proposição de indicadores quantitativos. 113 fls. Dissertação (Mestrado em Saúde e Produção Animal) - Programa de Pós-Graduação em Saúde e Produção Animal na Amazônia, Universidade Federal Rural da Amazônia, Belém, 2012.

BERTALANFFY, Ludwing. V. Teoria geral dos sistemas. Petrópolis: Vozes, 1973.

BRANCO, Samuel M. Ecossistêmica: uma abordagem integrada dos problemas do meio ambiente. São Paulo: Edgard Blücher, 1999.
BRASIL. Ministério da Saúde. Secretaria de Atenção à Saúde. Departamento de Atenção Básica. Saúde na Escola. Brasília: Ministério da Saúde, 2009. 96 p.: il. - (Série B. Textos Básicos de Saúde) (Cadernos de Atenção Básica; n. 24).

CÂMARA, Volney M.; TAMBELLINI, Anamaria T. Considerações sobre o uso da epidemiologia nos estudos em saúde ambiental. Revista Brasileira de Epidemiologia, Rio de Janeiro, v. 6, n. 2, p. 96-97, 2003.

CAPRA, Fritjof. O ponto de mutação. São Paulo: Cultrix, 2006.

CARVALHO, Vilson S. Raízes da ecologia social: o percurso interdisciplinar de uma ciência em construção. 382 fls. Tese (Doutorado em Psicossociologia de Comunidades e Ecologia Social) - Universidade Federal do Rio de Janeiro, Rio de Janeiro, 2005. 
CASTRO, Edna R. Território, biodiversidade e saberes de populações tradicionais. v. 92. Belém: Núcleo de Altos Estudos da Amazônia (NAEA) da Universidade Federal do Pará, 1998. p. 9-13.

CUSTÓDIO, Ivanir M. Influências da alimentação na aprendizagem, 2008. Disponível em: <www.diaadiaeducacao.pr.gov.br/ portals/pde/arquivos/1674-8.pdf $>$. Acesso em: 12 mar. 2012.

DABANCH, Jeannett P. Zoonosis. Revista Chilena de Infectologia, San Borja Arriarán, v. 20 (supl. 1), p. S47-S51, 2003.

DASZAK, Peter; CUNNINGHAM, Alfred A. Emerging infectious diseases: a key tole for conservation Medicine. In: AGUIRRE, Alonso. A. et al. (eds.). Conservation Medicine: ecological health in practice. New York: Oxford University Press, 2002. p. 443-449.

DESCOLA, Philipp. Estrutura ou sentimento: a relação com o animal na Amazônia. Revista Mana: Estudos de Antropologia Social, Rio de Janeiro, v. 4, n. 1, p. 23-45, 1998.

FERREIRA, Aurélio B. H. Novo dicionário da língua portuguesa. 2. ed. 35. impr. Rio de Janeiro: Nova Fronteira, 1986.

FREIRE, Paulo. Pedagogia da autonomia: saberes necessários à prática educativa. 26. ed. Rio de Janeiro: Paz e Terra, 2003.

GUIMARÃES, Mauro (org.). Caminhos da educação ambiental: da forma à ação. Campinas: Papirus, 2006 (Coleção Papirus Educação).

MORAES, Edmundo. C. Abordagem relacional: uma estratégia pedagógica para a educação científica na construção de um conhecimento integrado. In: ENCONTRO NACIONAL DE PESQUISA EM EDUCAÇÃO EM CIÊNCIAS, 4., Bauru, 2003. Anais... Disponível em: <http://fep.if.usp.br/ profis/ arquivos/ivenpec/Arquivos/Orais/ORAL027>. Acesso em: 14 dez. 2012.

ORGANISATION MONDIALE DE LA SANTÉ ANIMALE. Zoonoses transmissíveis por pri- matas não humanos. Cap. 2.10.1; art. 2.10.1.1. 2008. Paris, França. Disponível em: <www. rr-africa.oie.int/docspdf/en/Codes/codigo/ 15.pdf>. Acesso em: 20 dez. 2011.

PALHA, Maria D. C. A medicina veterinária e o meio ambiente. Revista Amazônia Típica, Belém, n. 5, p. 11-13, 2012.

PALHA, Maria D. C.; SARDINHA, Ana S. A.; HAMOY, Moisés B. R. Levantamento de fauna em duas comunidades de várzea da Amazônia Oriental. In: FANG, Tula G.; MONTENEGRO, Olga L.; BODNER, Richard E. (orgs). Manejo y conservación de fauna silvestre en América Latina. Santa Cruz, Bolívia: Editorial Instituto de Ecología, 1999.

PALHA, Maria D. C.; TOURINHO, Manoel. M. Religiosidade e racionalismo ambiental no estuário do rio Amazonas. In: GAMA, João R. V.; PALHA, Maria D. C.; SANTOS, Silvio R. M. (orgs.). A natureza e os ribeirinhos. Belém: Ufra, 2009. p. 15-26.

PARSONS, Talcott. The social system. New York: The Free Press, 1951.

PENTEADO, Heloisa. D. Meio ambiente e formação de professores. São Paulo: Cortez, 2007 (Coleção Questões de Nossa Época, 38).

PRIGOGINE, Ilya. O fim da ciência? In: SHNITMAN, Fried D.(org.). Novos paradigmas, cultura e subjetividade. Porto Alegre: Artes Médicas, 1996.

REDFORD, Kent H. A floresta vazia. In: VALLARES-PÁDUA, Claudio; BODMER, Richard E.; CULLEN-JUNIOR, Laury (orgs.). Manejo e conservação de vida silvestre no Brasil. Belém: MCT/CNPq/Sociedade Civil Mamirauá, 1997. p. 1-22.

REIGOTA, Marcos. A floresta e a escola: por uma educação ambiental pós-moderna. 2. ed. São Paulo: Cortez, 2002.

SANTOS-FITA, Didac; COSTA-NETO, Eraldo M. As interações entre os seres humanos e os animais: a contribuição da etnozoologia. Biotemas, Florianópolis, v. 20, n. 4, p. 99-110, dez. 2007. 
SILVA, Andréa L. Animais medicinais: conhecimento e uso entre as populações ribeirinhas do Rio Negro, Amazonas, Brasil. Boletim do Museu Paraense Emílio Goeldi-Ciências Humanas, Belém, v. 3, n. 3, p. 343-357, set./dez. 2008.
WHITFIELD, Gibbons J. et al. The global decline of reptiles. BioScience, American Institute of Biological Sciences, Oxford University, v. 50, n. 8, p. 653-654, August, 2000.

Recebido em 27/05/2013

Aprovado em 27/10/2014 